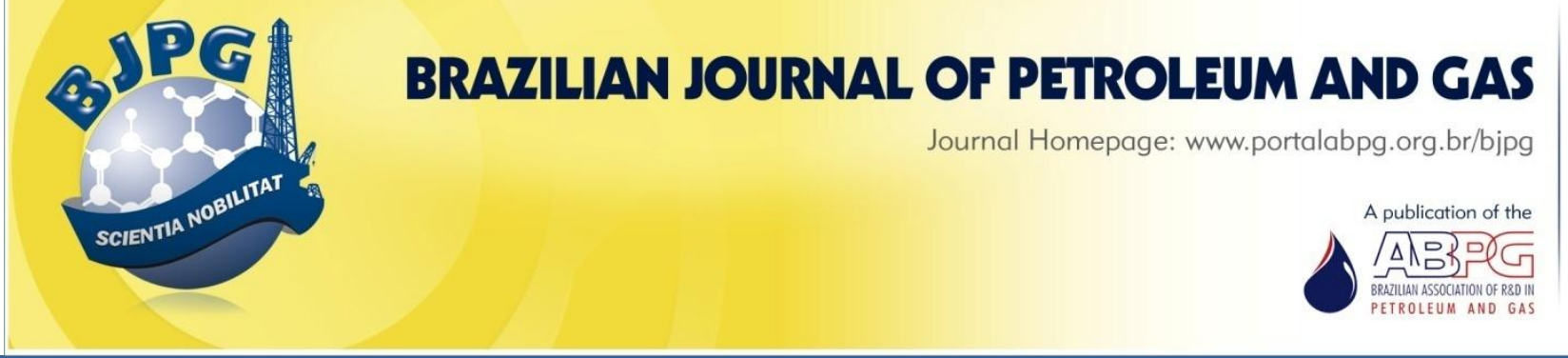

\title{
LABORATORY STUDY ON CARBONATE ROCKS CHARACTERIZATION AND POROSITY CHANGES DUE TO $\mathrm{CO}_{2}$ INJECTION
}

\author{
${ }^{\text {a }}$ Monte-Mor, L. S. ${ }^{1}{ }^{\text {a }}$ Trevisan, O. V. \\ a Departamento de Engenharia de Petróleo, Faculdade de Engenharia Mecânica, Universidade Estadual de Campinas - \\ UNICAMP, SP, Brasil \\ Received: 10.03.2016 / Revised: 07.06.2016 / Accepted: 09.06.2016 / Published on line: 12.07.2016
}

\begin{abstract}
Enhanced oil recovery methods must be improved continuously to provide higher recovery factors for the new fields under development in a globally competing market. $\mathrm{CO}_{2}$ injection processes in carbonate rocks involve reactions between acid brine and the rock. These interactions promote petrophysical changes in the rock structure due to calcite dissolution or precipitation. Lab experiments in saturated coquina samples were carried out to better understand the effects on porosity by $\mathrm{CO}_{2}$ injection. X-ray Photoelectron Spectrometer (XPS) was used to analyze the surface chemistry of the rock sample for elemental composition measurement. X-Ray Micro-CT and Mercury Injection Capillary Pressure (MICP) were carried out to calculate mean porosity in the rock sample. X-Ray scans were run for each pore volume injected. The results show that dissolution should be considered when supercritical $\mathrm{CO}_{2}$ is injected in the reservoir. This process has relevance for project design, risk analysis, economic evaluation and reservoir behavior forecast.
\end{abstract}

\section{KEYWORDS}

rock characterization; $\mathrm{CO}_{2}$ injection; reservoir engineering; enhanced oil recovery; chemical reactions

\footnotetext{
${ }^{1}$ To whom all correspondence should be addressed.

Address: Departamento de Engenharia de Petróleo, Faculdade de Engenhaira Mecânica, Universidade Estadual de Campinas UNICAMP- R.Mendeleyev, 200 - Cidade Universitária, Campinas - SP.

ZIP Code: 13083-860 | Telephone: +55 19 99211-7575 |e-mail: Imonte@dep.fem.unicamp.br doi:10.5419/bjpg2016-0009
} 


\section{INTRODUCTION}

One of the main challenges for reservoir engineering is the disposal of carbon dioxide $\left(\mathrm{CO}_{2}\right)$ generated during oil production from $\mathrm{CO} 2$-rich reservoirs. Recent reports on the potential of presalt reservoirs mention deposits up to 7,000 meters deep, containing light oil of low acidity and low sulfur content, along with about 3.1 billion tons of carbon dioxide, which occupies about $10 \%$ to $15 \%$ of the reservoir volume (Carbon Capture Journal, 2010). Cost reduction has been constantly discussed for the application of carbon capture and storage (CCS). Carbon dioxide when in contact with other components presents a corrosive characteristic, which leads to an increase in project costs. A common solution presented is the injection of $\mathrm{CO}_{2}$ into the reservoir with a twofold objective: (1) to improve oil recovery and (2) to reduce emission costs. However, injection of $\mathrm{CO}_{2}$ into carbonate rocks brings new problems, diverse from those associated with injection of other fluids for oil recovery (Meyer, 2007).

In the pre-salt area, oil companies intend to adopt technologies of carbon capture and sequestration on the reservoir itself to reduce emissions of gases that occur during oil extraction. The fluid flow and mass transfer behavior of the injected carbon dioxide in the porous rock saturated with oil is highly relevant for the areas of project design, risk analysis, economic evaluation, and field development strategy.

Regardless of the rock composition, gradual dissolution of $\mathrm{CO}_{2}$ into the formation water (generally in thermodynamic equilibrium with the rock-forming minerals) leads to a decrease in $\mathrm{pH}$. As a result, the main process involves the dissolution of carbonates and possibly silicates, depending on the kinetics of individual responses. Near the injection well, where the unbalance is greater, the dissolution of solid processes may affect the mechanical properties and fluid dynamic of the rock irreversibly. Specifically, the dissolution leads to an increase in porosity and permeability, as well as to changes in the reactive surface area of the mineral. On the other hand, increased cation concentration produced by carbonate dissolution can supersaturate the fluid ahead in the flow front. In this case, it is expected that precipitation would lead to a decrease in porosity and permeability (Luquot et al., 2009; Egermann et al., 2005; Andreani et al., 2009; Hoefner \& Fogler, 1988).
The aim of this paper is to characterize and study the effects of $\mathrm{CO}_{2}$ saturated brine injection in carbonate rocks. The study had an experimental stage with tests involving the co-injection of $\mathrm{CO}_{2}$ and brine in samples of calcareous rocks. The study focuses on the temporal effects of permeability and porosity of the rock during injection. The experiments will use non-destructive techniques (X-ray Photoelectron Spectrometer, tomography, and micro tomography) and mercury injection capillary pressure (MICP) for rock characterization and to quantify the texture changes in the rock and, eventually, identify the porous sub-systems most affected by the reactions. The X-ray Photoelectron Spectrometer (XPS) analyses were developed at LNNano - Brazilian Nanotechnology National Laboratory, CNPEM/MCTI and the Micro tomography at Petrobras Research and Development Center (CENPES).

\section{MATERIALS AND METHODS}

\subsection{Calcite chemical reactions}

The system composed by $\mathrm{CO}_{2}(\mathrm{~g})-\mathrm{H}_{2} \mathrm{O}-\mathrm{CaCO}_{3}$ produces, by chemical reactions, the most common acid in natural water systems the carbonic acid. A series of chemical reactions occur in the system (Al-Shalabia et al., 2014):

$\mathrm{CO}_{2}(\mathrm{~g}) \leftrightarrow \mathrm{CO}_{2}(\mathrm{aq})$

$\mathrm{CO}_{2}(\mathrm{~g})+\mathrm{H}_{2} \mathrm{O} \rightarrow \mathrm{H}_{2} \mathrm{CO}_{3}$

$\mathrm{H}_{2} \mathrm{CO}_{3} \rightarrow \mathrm{H}^{+}+\mathrm{HCO}_{3}$

$\mathrm{HCO}_{3}^{-} \rightarrow \mathrm{H}^{+}+\mathrm{CO}_{3}^{2}$

$\mathrm{CaCO}_{3} \rightarrow \mathrm{Ca}^{2+}+\mathrm{CO}_{3}^{2-}$

$\mathrm{CO}_{2}(\mathrm{~g})+\mathrm{H}_{2} \mathrm{O}+\mathrm{CaCO}_{3} \rightarrow \mathrm{Ca}^{2+}+2 \mathrm{HCO}_{3}$

Equations (1) and (2) show the carbonic acids formed by $\mathrm{CO}_{2}$ dissolution in water where $\mathrm{CO}_{2}(\mathrm{~g})$ becomes $\mathrm{CO}_{2}(\mathrm{aq})$ and associates with water molecules. Depending on the formation $\mathrm{pH}$, calcite is affected directly by the formed carbonic acid. The acid is dissociated according to Equations (3) and (4). The calcite dissolution is given by Equation (5), and the summarized effect of calcite dissolution by $\mathrm{CO}_{2}$ injection can be expressed by Equation (6). It is worth to remind that calcite dissolution and precipitation in the presence of $\mathrm{CO}_{2}$ 
changes with temperature, pressure, and $\mathrm{pH}$ conditions.

Reactions occur in batch systems searching for a chemical equilibrium or while fluids are flowing across the porous medium. In the latter case, the reactive transport phenomena are governed by Péclet and Damköhler numbers for small numbers of Reynolds (Fogler \& Rege, 1986; Daccord et al., 1993; Golfier et al., 2002).

The Péclet number represents the relative importance of mass transport by convection and diffusion (Buijse, 1997).

$P e=\frac{v l}{D e}$

Where:

$v=$ interstitial velocity;

$l=$ typical length scale;

$D e=$ molecular diffusion coefficient

The Damköhler number describes the ratio of the reaction rate to the advection rate (Buijse, 1997).

$\mathrm{Da}=\frac{k l}{v}$

Where:

$k=$ reaction rate;

$l=$ typical length scale;

$v=$ interstitial velocity
At high values of $\mathrm{Pe}$ and Pe.Da, a dominant channel (wormhole) is formed and a large increase in permeability is expected due to the dissolution process. For low values of Peand and high values Pe.Da, dissolution occurs mainly on the inner surface, leading to face dissolution. For very low values (Pe.Da), the dissolution is highly uniform. Figure 1 shows the relation between Damköhler and Péclet numbers to dissolution regimes.

\subsection{Rock characterization}

The rock samples used in this study were obtained from "Morro do Chaves" outcrop, "Coqueiro Seco" formation from the SergipeAlagoas Basin, in Brazil.

This carbonate outcrop consists of "coquina" rocks composed of bivalve lacustrine sediments, with discontinuity due to a diagenesis process. The rock presents similarities to some carbonate reservoirs within the rift section of the Brazilian pre-salt (Chinelatto, 2013; Belila, 2014). The samples have a diameter of $1.5 \mathrm{in}$ and $20 \mathrm{~cm}$ length (Figure 2) and were submitted to X-Ray Micro-CT. The sample used for X-Ray Photoelectron Spectroscopy was a cube of $2 \mathrm{~cm}$ side length.

\subsubsection{X-ray photoelectron spectroscopy (XPS)}

XPS is a technique for analyzing the surface chemistry of a material and can measure the elemental composition, empirical formula, chemical state, and electronic state of the

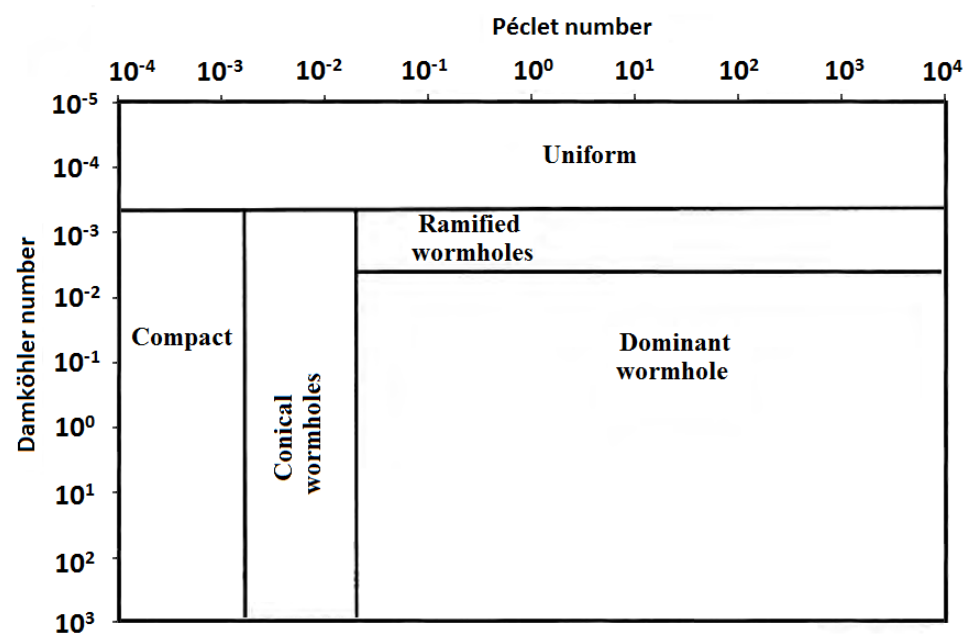

Figure 1. Wormhole formation regime vs. Damköhler and Péclet numbers (adapted from Golfier et al., 2002). 


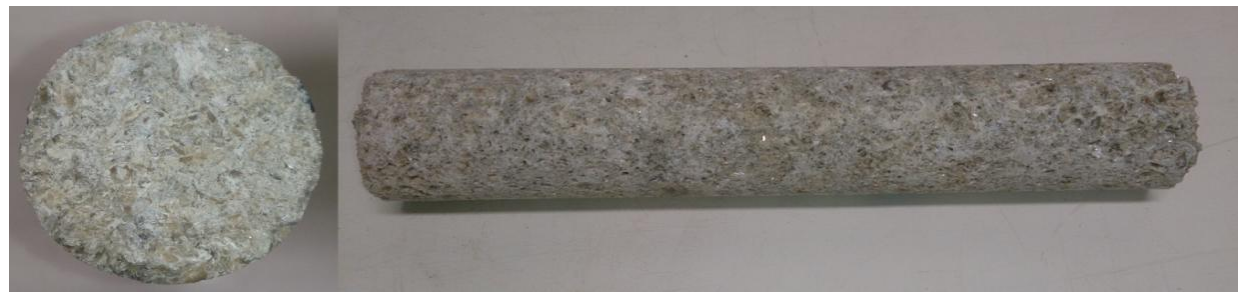

Figure 2. Sample of "Coquina" used in the experiments.

elements within a material (Thermoscientific Website, 2016). Most of the XPS studies identified the Ca (2p), C (1s) and O (1s) core-level shifts of calcium carbonate (Ni \& Ratner, 2008).

The analysis was performed to understand rock composition of $\mathrm{CaCO}_{3}$. The XPS was carried out in a Thermo Scientific K-Alpha ${ }^{\mathrm{TM}}+\mathrm{X}$-ray Photoelectron Spectrometer. The aim of the paper is to study the reactions that cause dissolution and precipitation between $\mathrm{CaCO}_{3}$ and $\mathrm{CO}_{2}$. Figure 3 shows the sample XPS picture. The analysis points were separated according to color. Different points were selected in the picture depending on the color presented. Three white points, three dark points, and three blue points (Matrix) were taken to analyze the surface.

A typical XPS wide scan spectrum from calcite is shown in Figure 4. All three elements comprising $\mathrm{CaCO}_{3}-\mathrm{Ca}, \mathrm{C}$, and O- were observed. Table 1 shows the atomic concentration for the nine points analyzed. Some Silicon (Si) was found and its presence is minimum compared to other main components. The presence of Aluminum (Al), Chlorine $(\mathrm{Cl})$, and Sodium ( $\mathrm{Na})$ was found as impurity. It should be noted that XPS uses surface layer analysis and impurities are commonly found.

As seen in Figure 4, almost only $\mathrm{Ca}, \mathrm{C}$, and $\mathrm{O}$ were observed on the surface. Residues of Aluminum ( $\mathrm{Al})$, Chlorine $(\mathrm{Cl})$, and Sodium $(\mathrm{Na})$ were found in the sample. These impurities may come from sodium carbonate, one of the reactants for the $\mathrm{CaCO}_{3}$ synthesis, or from the sample plugging operation.

\subsubsection{X-Ray Micro-CT}

X-Ray Micro-CT is a nondestructive technique that renders information, in two or three dimensions, on processes and variables of importance to subsurface flow and transport phenomena. Various studies use X-Ray Micro-CT

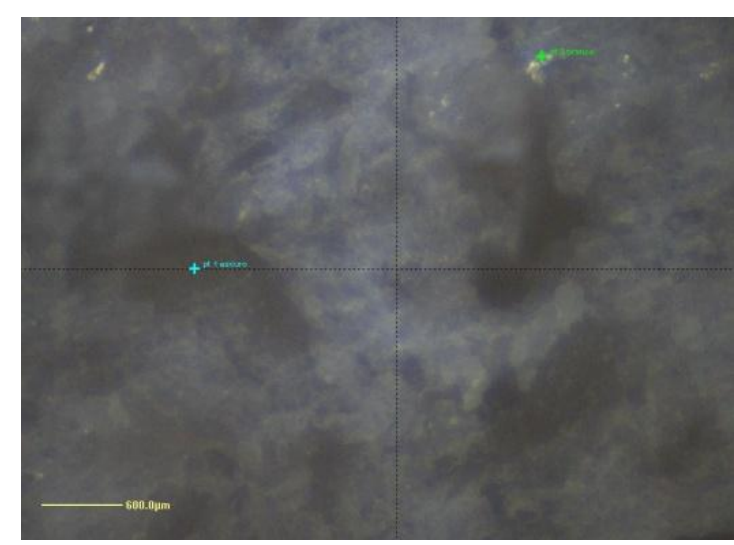

Figure 3. Image of the rock surface showing two out of the nine points picked for analysis.

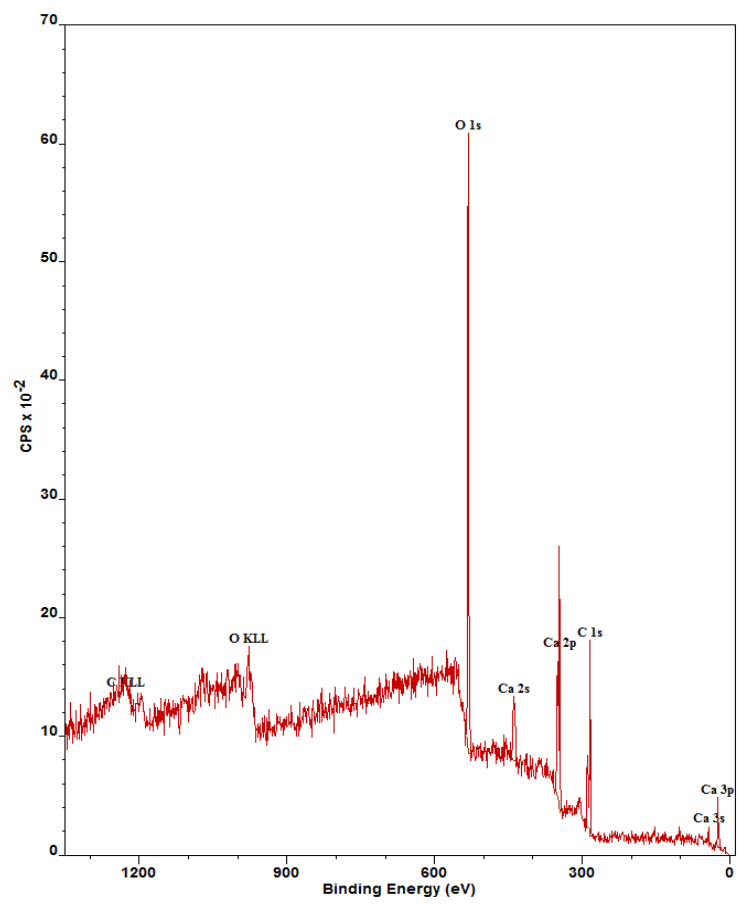

Figure 4. XPS wide scan of calcite showing that $\mathrm{Ca}$, $\mathrm{C}$, and $\mathrm{O}$ obtained at LNNANO facilities. 
Table 1. XPS atomic concentration (\%).

\begin{tabular}{ccccccccccc}
\hline Element & White 1 & White 2 & White 3 & Dark 1 & Dark 2 & Dark 3 & Matrix 1 & Matrix 2 & Matrix 3 & Average \\
\hline O 1s & 30.61 & 32.15 & 29.31 & 22.02 & 23.61 & 33.49 & 30.79 & 30.02 & 31.06 & 29.22889 \\
C1s & 36.19 & 29.3 & 33.92 & 46.56 & 41.64 & 21.77 & 26.11 & 33.93 & 23.48 & 32.54444 \\
Ca 2p & 9.65 & 9.00 & 10.39 & 6.91 & 7.38 & 5.83 & 9.17 & 7.05 & 9.98 & 8.373333 \\
Ca 2s & 5.76 & 4.79 & 6.53 & 4.23 & 4.59 & 3.66 & 5.68 & 3.82 & 6.41 & 5.052222 \\
Ca 3s & 4.86 & 5.84 & 5.64 & 5.57 & 6.01 & 4.60 & 7.14 & 4.34 & 7.44 & 5.715556 \\
Ca 3p & 12.93 & 12.27 & 14.21 & 11.16 & 12.84 & 11.32 & 16.18 & 12.56 & 17.14 & 13.40111 \\
Si 2p & - & 3.98 & - & 1.61 & 1.72 & 7.30 & 2.61 & 4.57 & 1.29 & 2.564444 \\
Si 2s & - & 2.67 & - & 1.49 & 1.71 & 6.18 & 2.32 & 3.71 & 1.41 & 2.165556 \\
Cl 2p & - & - & - & 0.45 & 0.50 & - & - & - & 0.82 & 0.195556 \\
$\mathrm{Al} 2 \mathrm{p}$ & - & - & - & - & - & 2.72 & - & - & - & 0.302222 \\
$\mathrm{Al} 2 \mathrm{~s}$ & - & - & - & - & - & 3.13 & - & - & - & 0.347778 \\
$\mathrm{Na} \mathrm{1s}$ & - & - & - & - & - & - & - & - & 0.97 & 0.107778 \\
\hline
\end{tabular}

for rock characterization and for reactive transport phenomena studies (Gharbi et al., 2013; Andrew et al., 2014; Amin et al., 2014; Mattilaa et al., 2016). The X-Ray Micro-CT was carried out in a GE Phoenix V|Tome |x L300 X-Ray Micro-CT.

The image analysis consisted of the use of common image processing techniques such as contrast handling, segmentation, erosion, and dilation. Our study used the MIPAR software (Sosa et al., 2014), developed by the Center for the Accelerated Maturation of Materials (CAMM) at Ohio State University, for the 2D analysis. Figures 5 and 6 show the pre and post-analysis of a sample slice.

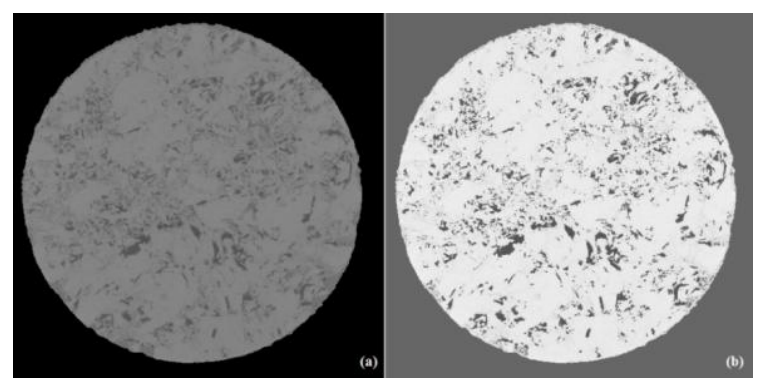

Figure 5. Image slice obtained from X-Ray Micro-CT: 5a original image; 5b overlay with 30\% opacity.
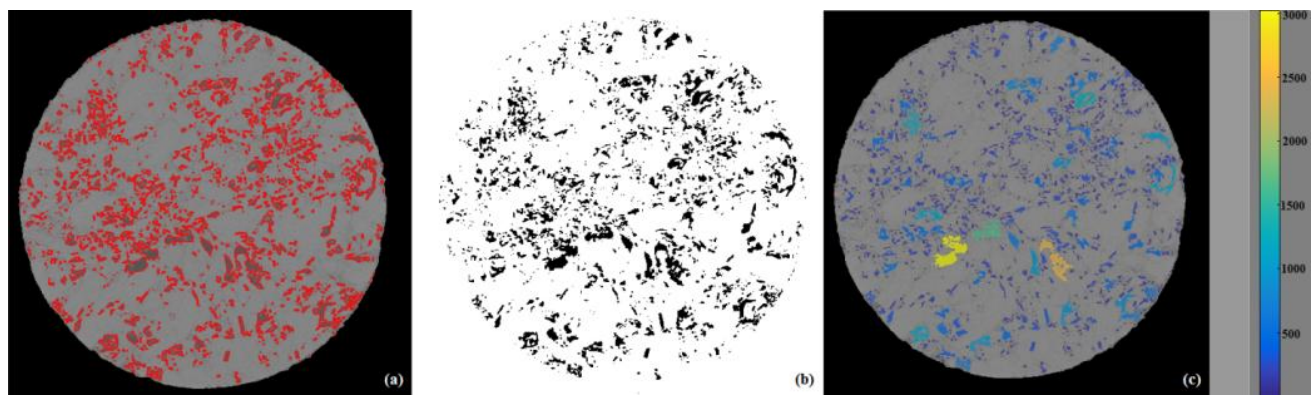

Figure 6. Images from X-Ray Micro-CT: 6a outline of pore walls; black and white image with pores in black; and 6c number of pixels present in each pore. 


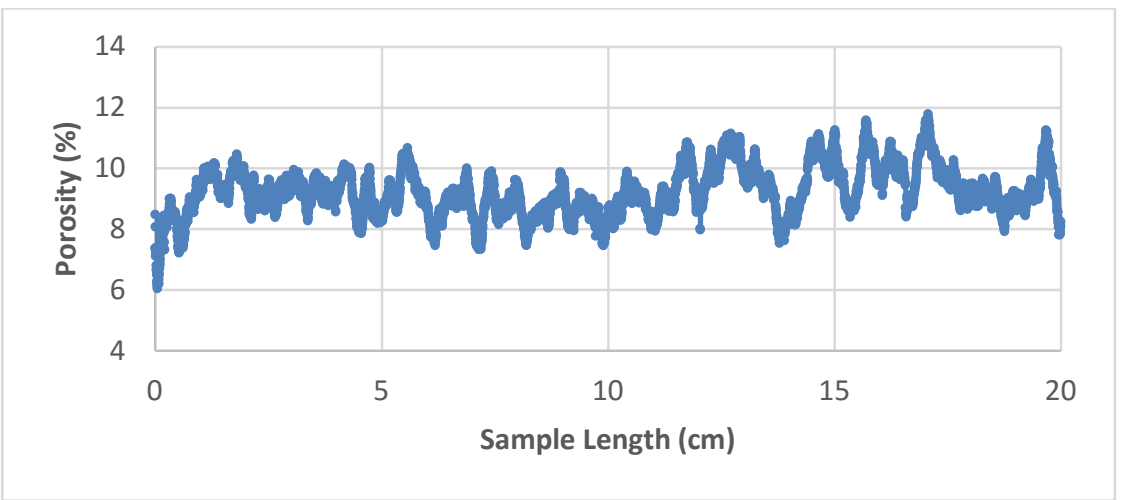

Figure 7. Porosity along the sample length.

Figure 7 shows the porosity along the sample length. The X-Ray Micro-CT data set is composed by 5,866 slices along the $20 \mathrm{~cm}$ sample length. The porosity was calculated at each slice. As seen on the plot, porosity varied between $6.04 \%$ and $11.79 \%$ (minimum and maximum porosities found at slices). The average porosity calculated for the entire data set was $9.23 \%$.

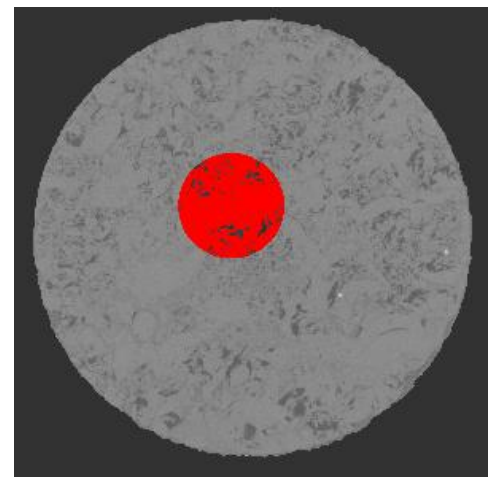

Figure 8. Analyzed Volume of Interest (VOI) in the investigated sample.

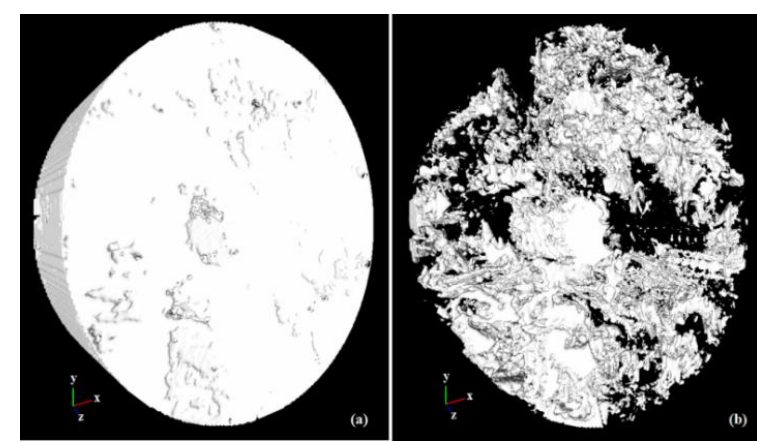

Figure 9. Volumes rendering: a) solid volumes b) pore network.
A 3D image was created to show the sample reconstruction after the X-Ray Micro-CT data. Typically, the starting point of the 3D image analysis consists of the extraction of a representative Volume of Interest (VOI), usually denoted as Representative Elementary Volume (REV) in the assumption that the porous space is represented by the sample under investigation (Brun et al., 2010). Although there are suggested rules for REV size determination (Bear, 1972), the process itself is handled on a case-by-case situation by the user. In this study, we used the iMorph software (Brun et al., 2008; Brun et al., 2009) for $3 \mathrm{D}$ reconstruction and analysis.

Figure 8 shows the VOI (red area) used in the analysis. The X-Ray Micro-CT generates 5,866 slices representing an analyzed volume of $1214 \times 1199 \times 5866$ in $20 \mathrm{~cm}$ length. The need of a powerful computer interfered in the image analysis and segmentation was necessary to continue the analysis. We used only 59 slices, representative of the analyzed volume of $269 \times 269 \times 59$ pixels, which represented $2 \mathrm{~mm}$ length in the sample. It is worth reminding that such value represents the minimum distance between two slices of a conventional tomography. Figures $9 a$ and $9 b$ show the volume rendering of the sample and the pore network, respectively. The average porosity calculated in the VOI was $9.76 \%$.

\subsubsection{Mercury injection capillary pressure (MICP)}

Mercury intrusion capillary pressure (MICP) test is a common technique to evaluate the porethroatsize distribution. In a mercury intrusion test, the non-wetting Mercury invades the connected pore system according to the imposed pressure 


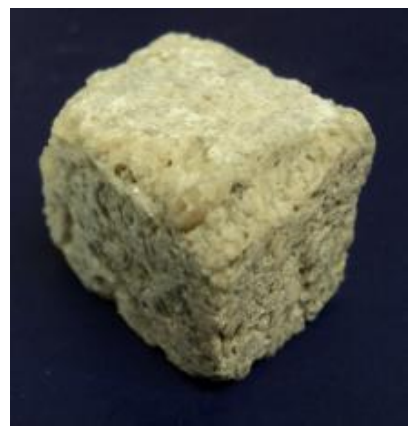

Figure 10. MICP test sample.

(Qajar, 2012). Figure 10 shows the sample $(2 \mathrm{~cm} x$ $2 \mathrm{~cm} \times 2 \mathrm{~cm}$ ) that was subjected to MICP. The mercury injection was carried out in a Micrometrics Autopore IV 9500 porosimeter.
First, the sample was inserted into a lowpressure chamber and submitted to vacuum. The operating range adopted in this step was 0.5 to 20 psi. After the mercury filling in a low- pressure operation, the sample was moved to the highpressure chamber where pressure ranged from 20 to $60000 \mathrm{psi}$. At each set pressure value, the intruded mercury volume was registered. The set of measurements provided a curve of cumulative volume of mercury to successive pressure increases (Figure 11). The pore-throat diameter associated to the incremented volume is represented in Figure 12.

The measured porosity of $10.96 \%$ is consistent with those found in the literature (Chinelatto, 2013; Belila, 2014). The maximum pore-throat diameter value found was $401.5 \mu \mathrm{m}$ and the

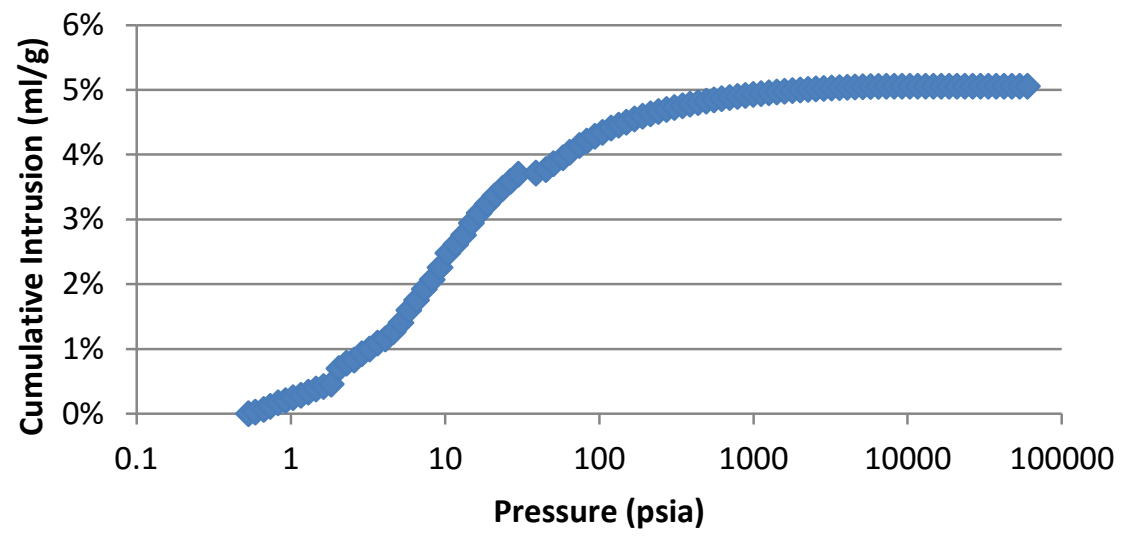

Figure 11. Cumulative Intrusion vs. Pressure for MICP test

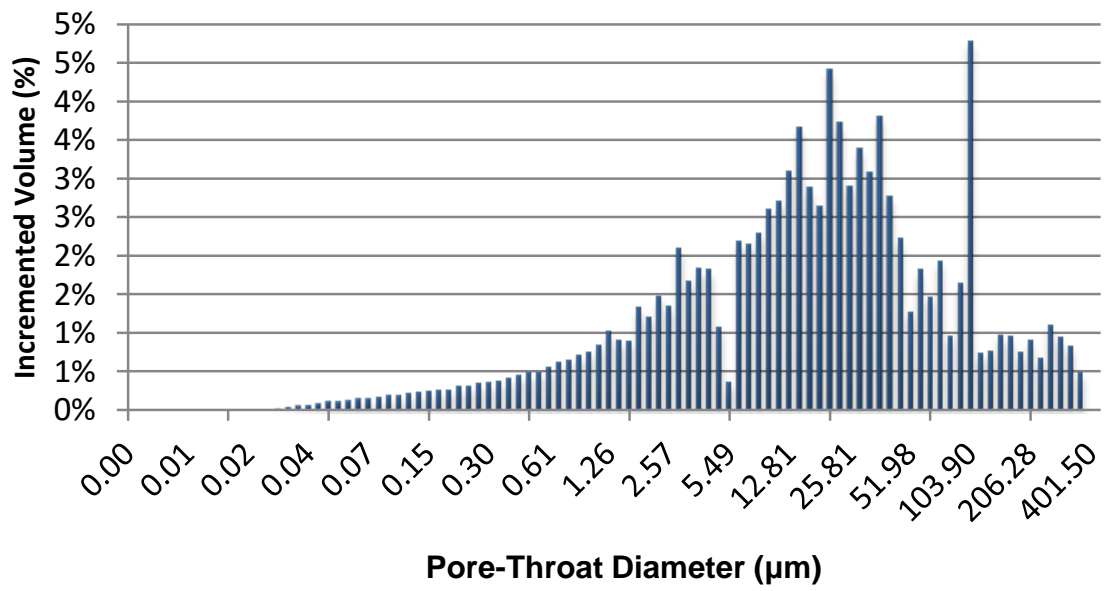

Figure 12. Incremented volume vs. Pore-Throat Diameter. 


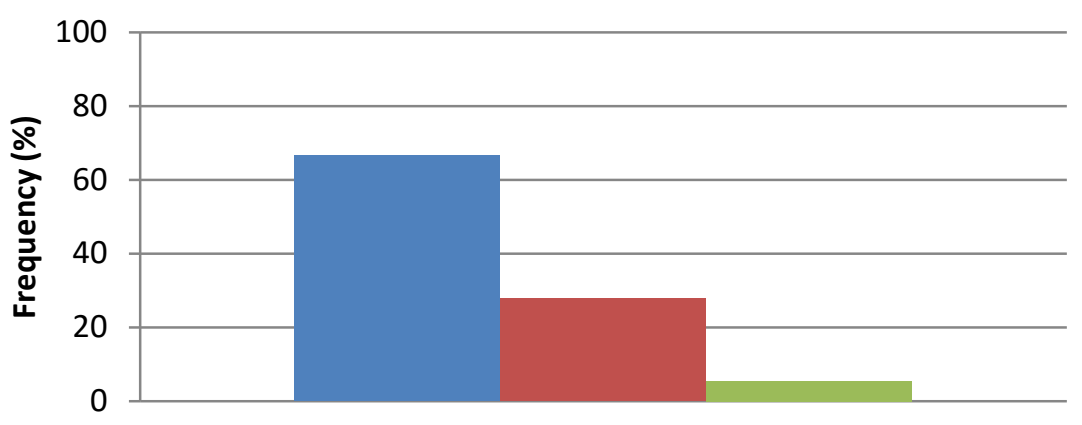

Macropores Mesopores Micropores

Figure 13. Histogram showing the distribution of pore-throat sizes.

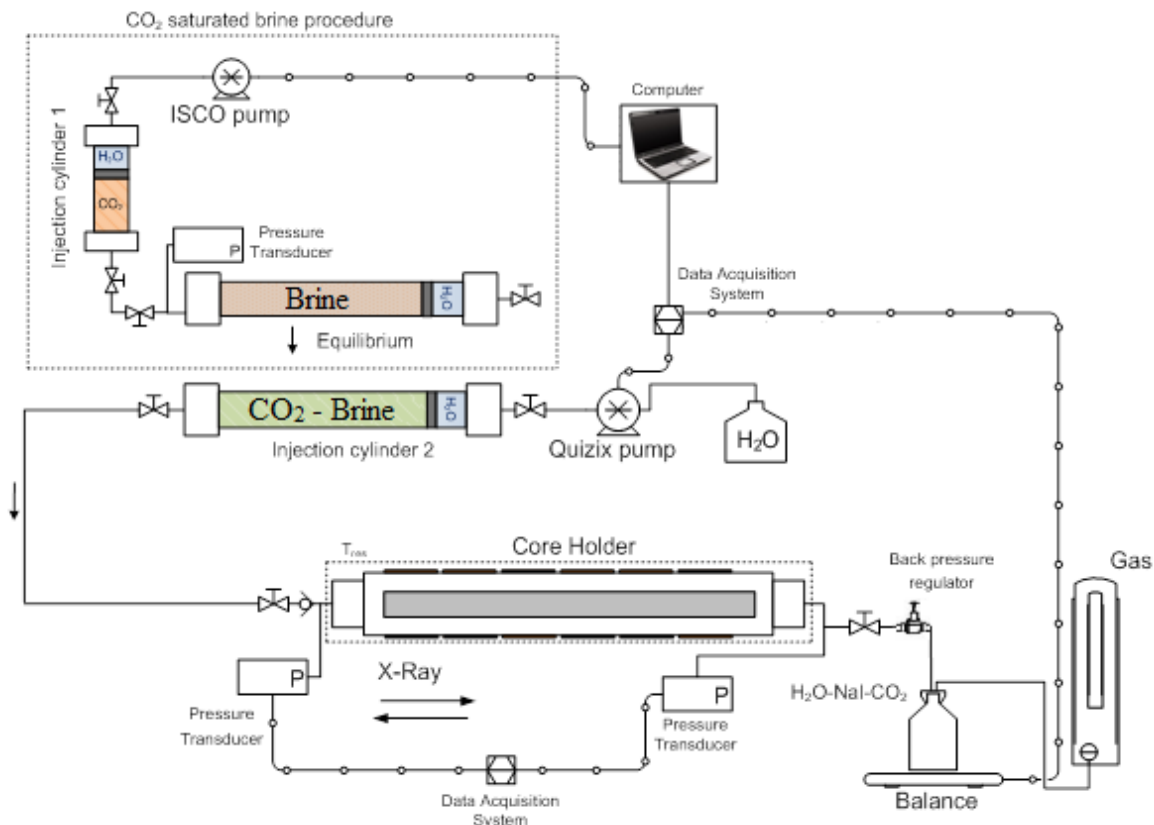

Figure 14. Experimental apparatus for $\mathrm{CO}_{2}$ saturated brine injection.

minimum $0.01 \mu \mathrm{m}$, but one can observe that the rock is formed, mostly, by large pores. Figure 13 shows the percent frequency interval between macropores, mesopores, and micropores (Marzouk et al., 1995; Ramamoorthy et al., 2008; Machado et al., 2011). The sample has $5.48 \%$ of micropores, $27.97 \%$ of mesopores, and $66.55 \%$ of macropores.

Table 2. Porosity values for different methods of measurement.

\begin{tabular}{lcc}
\hline \multicolumn{1}{c}{ Method } & Analysis & Mean porosity (\%) \\
\hline X-Ray Micro-CT Scan & 2D & 9.23 \\
X-Ray Micro-CT Scan & 3D & 9.76 \\
MICP & - & 10.96 \\
\hline
\end{tabular}

Although few micropores are present, the distribution is heterogeneous (large diameter variation). The results obtained by Micro-CT and MICP are shown in Table 2 with porosities ranging from $9.23 \%$ to $10.96 \%$.

\subsection{Description and application of equipment and processes}

The experimental apparatus used in the displacement study is located at the University of Campinas. Figure 14 shows the experimental setup scheme. The injection system includes fluid supply cylinders, automatic high-pressure pumps, and flow meters. All equipments are specified to operate with corrosive fluids at high pressures and temperatures. The high-pressure cylinders, tubes 
Table 3. Brine composition in wt. \%.

\begin{tabular}{cccccccccc}
\hline $\mathrm{NaCl}$ & $\mathrm{BaCl}_{2}$ & $\mathrm{KCl}$ & $\mathrm{MgCl}_{2}$ & $\mathrm{CaCl} 2$ & $\mathrm{SrCl}_{2}$ & $\mathrm{KBr}$ & $\mathrm{NaHCO}_{3}$ & $\mathrm{LiCl}$ & $\mathrm{Na}_{2} \mathrm{SO}_{4}$ \\
\hline 14.7356 & 0.0004 & 0.7300 & 0.3289 & 2.4707 & 0.0358 & 0.0476 & 0.0076 & 0.0766 & 0.0117 \\
\hline
\end{tabular}

and valves, and connections are made of a highly resistant material to corrosive media and present a high mechanical strength. The system's maximum operating conditions are $10,000 \mathrm{psi}$ and $150{ }^{\circ} \mathrm{C}$, allowing reproducing reservoir conditions.

For the proper preparation of the rock sample, a protection system was developed for the rubber used in the core holder. The rubber usually enters the rock pores when subjected to overburden pressure. To avoid being exposed to this type of pressure, the sample is first wrapped with Teflon, then, in sequence, aluminum foil, and Teflon again. Finally, it is coated with retractable plastic materials encroached by heating. This procedure was used successfully for handling $\mathrm{CO}_{2}$ injection.

After being inserted in the core holder, the sample was submitted to a 3,000 psi overburden pressure and, then, it was cleaned. The cleaning procedure comprised a sequential injection of methanol $(1 \mathrm{ml} / \mathrm{min})$ at room temperature $\left(22{ }^{\circ} \mathrm{C}\right)$ to remove salts from the sample, toluene $(1 \mathrm{ml} / \mathrm{min})$ to remove organic components, and dry

Table 4. Sample properties.

\begin{tabular}{lc}
\hline \multicolumn{2}{c}{ Sample parameters } \\
\hline mass $(\mathrm{g})$ & 505.06 \\
length $(\mathrm{cm})$ & 20.2 \\
volume $\left(\mathrm{cm}^{3}\right)$ & 229.08 \\
permeability $(\mathrm{mD})$ & 128 \\
\hline
\end{tabular}

Table 5. Test injection rates.

\begin{tabular}{lc}
\hline \multicolumn{1}{c}{ Process } & Injection rate $(\mathrm{cc} / \mathrm{min})$ \\
\hline Saturation & - \\
Injection & 0.5 \\
Injection & 0.1 \\
Injection & 0.05 \\
\hline
\end{tabular}

nitrogen to help the drying process. Then, compressed air ( 6 bars) was injected for 48 hours to aid drainage. In sequence, rock porosity was determined by gas expansion technique using a nitrogen porosimeter Ultra-Pore 300 , and the absolute permeability with an Ultra-Perm 500, both from CoreLab Instruments.

The injected fluid was brine, saturated with sc$\mathrm{CO}_{2}$. Brine at high concentrations $(200,000 \mathrm{ppm})$ composed by a mixture of salts $\left(\mathrm{NaCl}, \mathrm{KCl}, \mathrm{MgCl}_{2}\right.$, $\mathrm{CaCl}_{2}, \mathrm{BaCl}_{2}, \mathrm{SrCl}_{2}, \mathrm{LiCl}, \mathrm{KBr}, \mathrm{Na}_{2} \mathrm{SO}_{4}$, and $\mathrm{NaHCO}_{3}$ ) was prepared to saturate the sample and compose the injected fluid. $X$-ray computed tomography (Xray $(\mathrm{CT})$, developed for medical purposes, was used to perform sample scanning during the experiment. The brine composition used is detailed in Table 3.

\section{RESULTS}

The tests were performed for three injection rates of brine saturated with sc- $\mathrm{CO}_{2}(0.05,0.1$, and $0.5 \mathrm{cc} / \mathrm{min}$ ) at $25^{\circ} \mathrm{C}$ and $2,000 \mathrm{psi}$. The confining pressure was constant and equal to 3,000 psi. At each different injection rate, a total of 4 pore volumes were injected. At the completion of each pore volume, a CT scan was held to check porosity changes along the sample. Table 4 shows the sample initial properties. Table 5 shows the tested injection rates.

Figure 15 shows the evolution of the average porosity obtained by CT scan along the development of the tests with three different injection rates and with a standard deviation of 0.31 . During the injection of the first 2 pore volumes the average porosity increased, and in sequence the mean porosity dropped. This may have been due to the low flow rate that, after calcite dissolution, could not remove the solids through the porous network. After the injection of 4 pore volumes, at $\mathrm{q}=0.1 \mathrm{~cm}^{3} / \mathrm{s}$, porosity changes were less abrupt, although the flow rate was not 


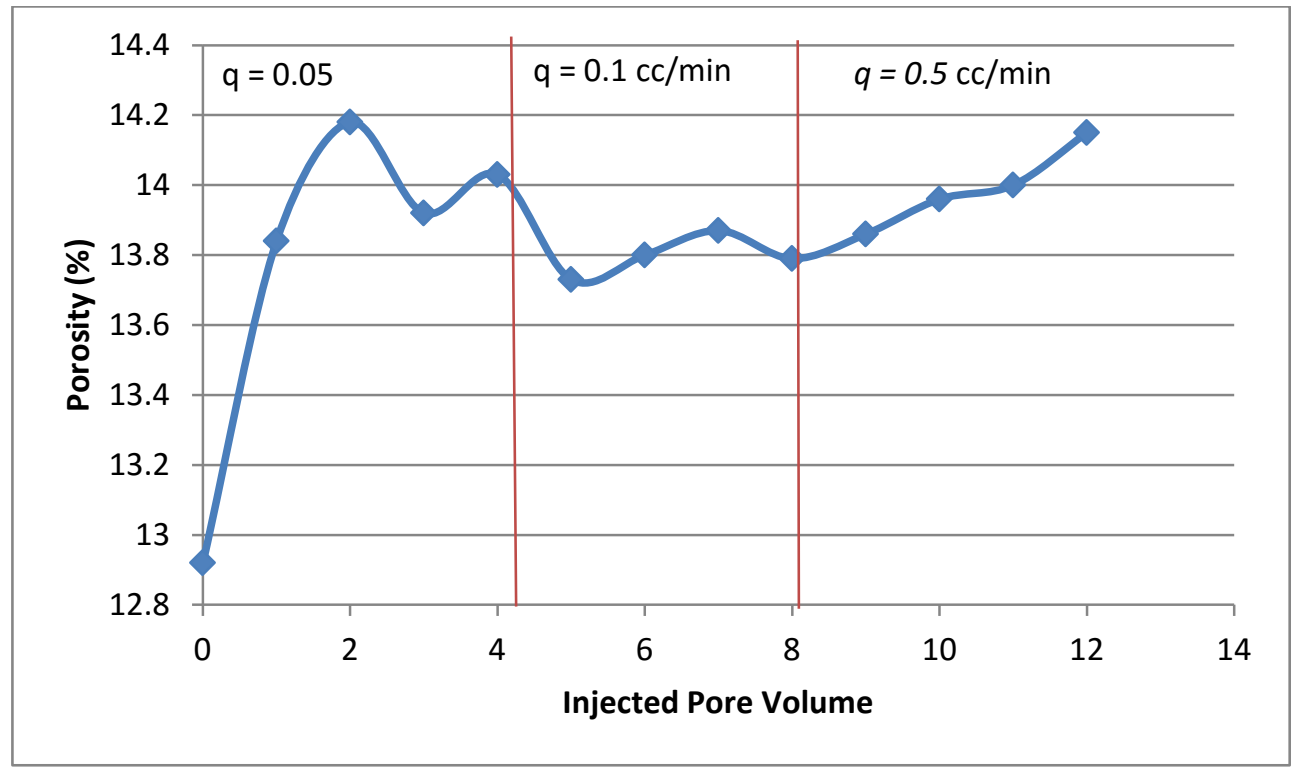

Figure 15. Mean porosity obtained by CT scan.

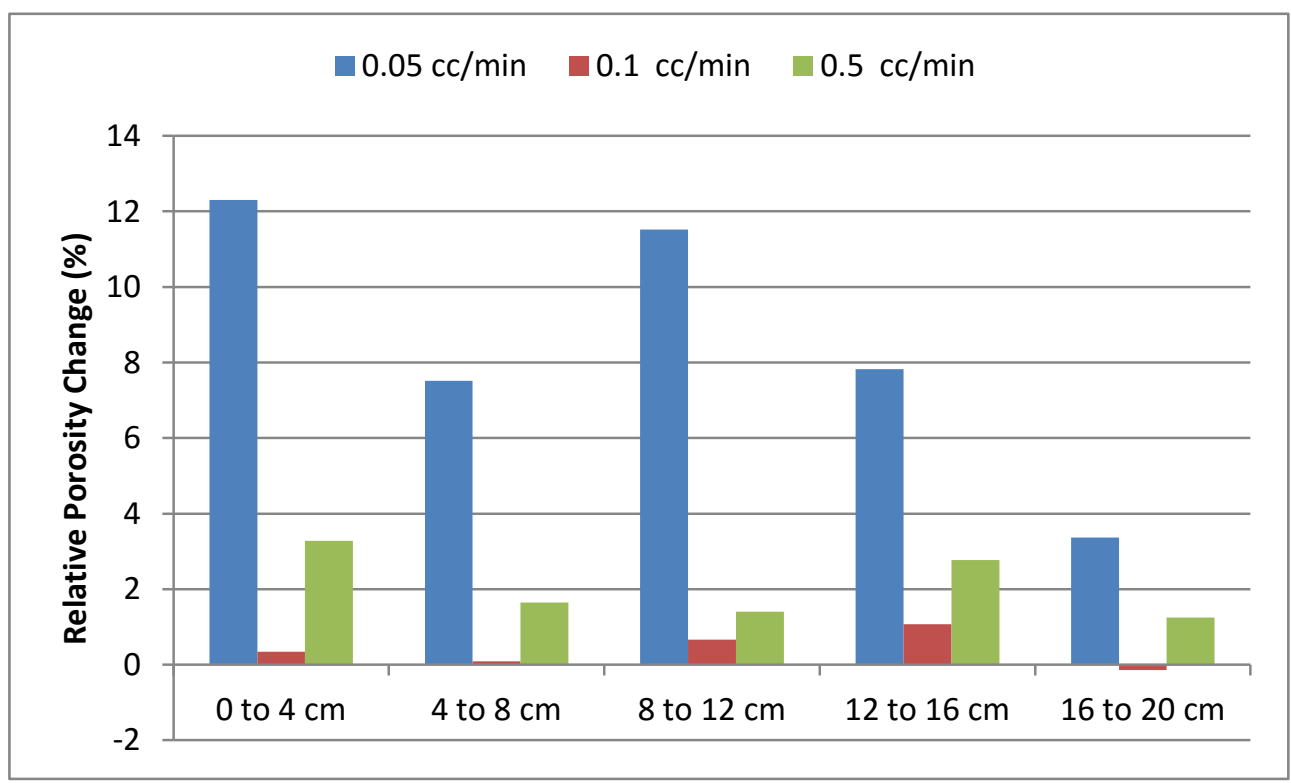

Figure 16. Relative porosity change for five segments composed by 4 centimeters for each injection rate.

too high, in fact, it was at the order of magnitude common in natural groundwater systems. After the injection described above, the reactions appeared to be strong in the first pore volumes injected during the process. At a high flow rate $(\mathrm{q}=0.5$ $\mathrm{cm}^{3} / \mathrm{s}$ ), there was a persistent increase in porosity. The occurrence was probably due to dragging of the loose grain out of the plug by the high flow rate.

To improve the visualization of the porosity changes in the sample, Figure 16 shows the relative porosity change for five segments composed by 4 centimeters for each injection rate. There is a high porosity change in the first regions (injection well) compared to the last regions (towards the production well). As a general rule, non-uniform dissolution is expected to occur with the first pore volumes injected and near the injection well in calcite-rich reservoirs because of the high reactivity of calcite at low pH conditions. As the flow moves down the sample, the chemical potential of $\mathrm{CO}_{2}$ brine solution is reduced and dissolution becomes less effective. 


\section{CONCLUSIONS}

The rock characterization by XPS technique showed that the rock composition is formed practically by $\mathrm{CaCO}_{3}$. Peaks of $\mathrm{Ca}, \mathrm{C}$, and $\mathrm{O}$ were clearly dominant, with some traces of Aluminum (Al), Chlorine ( $\mathrm{Cl})$, and Sodium ( $\mathrm{Na}$ ) also found in the sample. These impurity traces may come from the sodium carbonate, one of the reactants for $\mathrm{CaCO}_{3}$ synthesis, or introduced by the sample plugging operation.

The porosity characterization through X-Ray Micro-CT and through MICP show a good correlation between the values found. The 2DX-Ray Micro-CT analysis using MIPAR Software found 5,866 porosity values through the $20 \mathrm{~cm}$ length. The mean porosity of 9.23 is close to that found in the 3D analysis $(9.76 \%)$ using iMorph software. One must be cautious when analyzing 3D porosity as it depends on the REV size determination. The MICP analysis showed a porosity value of $10.96 \%$. The techniques furnish the pore size distribution. The maximum pore diameter value found was 401.5 $\mu m$ and the minimum $0.01 \mu \mathrm{m}$.

The results of the displacement test show the porosity changes due to supercritical $\mathrm{CO}_{2}$ enriched brine. The three different injection rates induced different behaviors to the changes. The first injected 2 pore volumes to promote an increase in porosity, but, then, the effect stabilized for a while. When the injection rate was increased to 0.5 $\mathrm{cc} / \mathrm{min}$ it seemed to expel the fine grains after the chemical dissolution re-starting the increase in the open pore volumes.

\section{ACKNOWLEDGEMENTS}

The authors would like to acknowledge the financial support provided by PETROBRAS and for the research support by LNNano - Brazilian Nanotechnology National Laboratory- and CNPEM/MCTI, for the collaboration with the XPS analysis. The authors would also like to recognize the following staff members: Wellington Fernando Marson, Washington Botine, and Erika Tomie K. Blini, of the Laboratory of Miscible Methods of Petroleum Recovery at the Center for Petroleum Studies, University of Campinas, Brazil.

\section{NOMENCLATURE}

$\mathrm{XPS}=\mathrm{X}$-ray Photoelectron Spectrometer

CNPEM = Brazilian Center for Research in Energy and Materials

CENPES $=$ Petrobras Research and Development Center

CAMM $=$ Center for the Accelerated Maturation of Materials

MIPAR = Materials Image Processing and Automated Reconstruction

VOI $=$ Volume Of Interest

REV $=$ Representative Elementary Volume

MICP = Mercury intrusion capillary pressure

\section{REFERENCES}

Al-Shalabia, E. W.; Sepehrnooria, K.; Pope G. Geochemical investigation of the combined effect of injecting low salinity water and carbon dioxide on carbonate reservoirs. Energy Procedia, v.63, p. 7663-7676, 2014.

http://dx.doi.org/10.1016/j.egypro.2014.11.800

Amin, S. M.; Weiss, D. J.; Blunt, M. J. Reactive transport modelling of geologic $\mathrm{CO}_{2}$ sequestration in saline aquifers: The influence of pure $\mathrm{CO}_{2}$ and of mixtures of $\mathrm{CO}_{2}$ with $\mathrm{CH}_{4}$ on the sealing capacity of cap rock at $37^{\circ} \mathrm{C}$ and 100 bar. Chemical Geology, v.367, p. 39-50, 2014.

http://dx.doi.org/10.1016/i.chemgeo.2014.01.002

Andreani, M.; Luquot, L.; Gouze, P.; Godard, M.; Hoise, E.; Gibert B. Experimental study of carbon sequestration reactions controlled by the percolation of $\mathrm{CO} 2$-rich brine through peridotites. Environmental Science \& Technology, v.43, p. 1226-1231, 2009.

http://dx.doi.org/10.1021/es8018429

Andrew, M.; Bijeljic, B.; Blunt M. J. Pore-scale imaging of trapped supercritical carbon dioxide in sandstones and carbonates. International Journal of Greenhouse Gas Control, v.22, p. 1-14, 2014. http://dx.doi.org/10.1016/j.ijggc.2013.12.018

Bear J. Dynamics of Fluids in Porous Media. New York: Elsevier, 1972. 
Belila, A. M. P. Caracterização petrofísica dos carbonatos da formação Morro do Chaves, Bacia Sergipe-Alagoas. Dissertação de Mestrado, Programa de Pós-Graduação em Geociências Universidade Estadual de Campinas, 2014. (in Portuguese)

Buijse, M. A. Mechanisms of wormholing in carbonate acidizing. International Symposium on Oilfield Chemistry. SPE-37283-MS, p. 683-686, Houston, Texas, 1997.

http://dx.doi.org/10.2118/37283-MS

Brun, E.; Vicente, J.; Topin, F.; Occelli, R. iMorph: A 3D morphological tool to fully analyse all kind of cellular materials. Cellmet'08, Dresden, Allemagne, 2008.

Brun, E.; Vicente, J.; Topin, F.; Occelli, R. iMorph: An open source software for 3D structural and geometrical analysis of porous material. Metfoam'09, Bratislava, Slovenie, 2009.

Brun, F.; Mancini, L.; Kasae, P.; Favretto, S.; Dreossi, D.; Tromba, G. Pore3D: A software library for quantitative analysis of porous media. Nuclear Instruments and Methods in Physics Research Section A, v.615, p. 326-332, 2010.

http://dx.doi.org/10.1016/j.nima.2010.02.063

Carbon Capture journal - Understanding CO2-EOR and its application in Brazil, 2010. Available at: http://www.carboncapturejournal.com/news/unde rstanding-co2-eor-and-its-application-inbrazil/2832.aspx?Category=all. Accessed on: 01 January 2016.

Chinelatto, G. F. Caracterização permo-porosa a partir da análise de imagens das coquinhas da Formação Morro do Chaves, Bacia SergipeAlagoas, Brasil. Trabalho de Conclusão de Curso, Instituto de Geociências, Universidade Estadual de Campinas, 2013.

Daccord, G.; Lenormand, R.; Lietard, O. Chemical dissolution of a porous medium by a reactive fluid-1 model for the "wormholing" phenomenon. Chemical Engineering Science, v. 48(1), p. 169-178, 1993.

http://dx.doi.org/10.1016/0009-2509(93)80293-Y
Egermann, P.; B., Bazin; Vizika, O. An experimental investigation of reaction-transport phenomena during $\mathrm{CO}_{2}$ Injection. SPE-93674-MS, SPE Middle East Oil and Gas Show and Conference, Kingdom of Bahrain, 2005. http://dx.doi.org/10.2118/93674-MS

Fogler, H. S.; Rege, S. D. Porous dissolution reactors. Chemical Engineering Communications, v. 42(4-6), p. 291-313, 1986.

http://dx.doi.org/10.1080/00986448608911747

Gharbi, O.; Bijeljic, B.; Boek, E.; Blunt, M. J. Changes in pore structure and connectivity induced by $\mathrm{CO}_{2}$ injection in carbonates: A combined porescale approach. Energy Procedia, v.37, p. 53675378, 2013.

http://dx.doi.org/10.1016/i.egypro.2013.06.455

Golfier, F.; Zarcone, C.; Bazin, B.; Lenormand, R.; Lasseux, D.; Quintard M. On the ability of a Darcyscale model to capture wormhole formation during the dissolution of a porous medium. Journal of Fluid Mechanics, v.457, p. 213-254, 2002. http://dx.doi.org/10.1017/S0022112002007735

Hoefner, M. L.; Fogler, H. S. Pore evolution and channel formation during flow and reaction in porous media. AIChE Journal, v. 34 (1), p. 45-54, 1988. http://dx.doi.org/10.1002/aic.690340107

Luquot, L.; Gouze P. Experimental determination of porosity and permeability changes induced by injection of $\mathrm{CO}_{2}$ into carbonate rocks. Chemical Geology, v. 265(1-2), p. 148-159, 2009.

http://dx.doi.org/10.1016/i.chemgeo.2009.03.028

Machado, V.; Frederico, P.; Netto, P.; Bagueira, R.; Boyd, A.; Souza, A.; Zielinski, I.; Junk E. Carbonate petrophysics in wells drilled with oilbase mud. SPWLA $\mathbf{5 2}^{\text {nd }}$ Annual Logging Symposium, Colorado Springs, USA, 2011.

Marzouk, I.; Takezaki, H.; Miwa, M. Geologic controls on wettability of carbonate reservoirs, Abu Dhabi, U.A.E. SPE-29883-MS, SPE Middle East Oil Show, Bahrain, 1995.

http://dx.doi.org/10.2118/29883-MS 
Mattilaa, K.; Puurtinena, T.; Hyväluomac, J.; Surmasd, R.; Myllysa, M.; Turpeinena, T.; Robertséne, F.; Westerholme, J.; Timonena, J. A prospect for computing in porous materials research: Very large fluid flow simulations. Journal of Computational Science, v.12, p. 62-76, 2016. http://dx.doi.org/10.1016/i.jocs.2015.11.013

Meyer, J. P. "Summary of Carbon Dioxide Enhanced Oil Recovery (CO2-EOR) Injection Well Technology", Contek Solutions - American Petroleum Institute, USA., 2007

Ni, M.; Ratner, B. D. Differentiation of calcium carbonate polymorphs by surface analysis techniques - An XPS and TOF-SIMS study. Surface and Interface Anaysis, v. 40(10), p. 1356-1361, 2008. http://dx.doi.org/10.1002/sia.2904

Qajar, J. Reactive Flow in Carbonate Cores via Digital Core Analysis. PhD Thesis, School of Petroleum Engineering, Faculty of Engineering, The University of New South Wales, 2012.
Ramamoorthy, R.; Boyd, A.; Neville, T.; Seleznev, N.; Sun, H.; Flaum, C.; Ma, J. A new workflow for petrophysical and textural evaluation of carbonate reservoirs. Paper B presented at the SPWLA 49th Annual Logging Symposium, Edinburgh, Scotland, 2008.

Sosa, J. M.; Huber, D. E.; Welk, B.; Fraser, H. L. Development and application of MIPAR: A novel software package for two- and three-dimensional microstructural characterization. Integrating Materials and Manufacturing Innovation, v. 3(10), p. 1-18, 2014. http://dx.doi.org/10.1186/2193-9772-3$\underline{10}$

Thermoscientific Website. What is X-Ray Photoelectron Spectroscopy (XPS)? Available at http://xpssimplified.com/whatisxps.php. Accessed on: 20 January 2016. 